\title{
Teaching clinical medical ethics: a model programme for primary care residency
}

\author{
Robert M Arnold, Lachlan Forrow, Steven A Wartman, Joan Teno Division of General Internal Medicine,
} Brown University Program in Medicine, USA

\section{Authors' abstract}

Few residency training programmes explicitly require substantive exposure to issues in medical ethics and fewer still have a formal curriculum in this area. Traditional undergraduate medical ethics courses teach preclinical students to identify ethical issues and analyse them at a theoretical level. Residency training, however, is the ideal time to establish the critical behavioural link which makes ethics truly useful in clinical medicine. The General Internal Medicine Residency Training Program at Rhode Island Hospital has developed an integrated, three-year curriculum with the goals of helping residents to perceive ethical issues in clinical practice, to utilise basic philosophical principles in resolving ethical dilemmas and to communicate these issues clearly and sensitively to patients. The curriculum has been well received by residents and has had a hospital-wide impact. We believe that training residents in medical ethics and communication skills is an effective approach to developing physicians' humane qualities.

\section{Introduction}

Perhaps in response to increasing complaints about the technological bias of medical education, the number of medical schools with course offerings in medical ethics in the humanities grew from 12 pilot programmes in 1972 to 89 in 1980 (1). These traditional undergraduate medical ethics programmes teach preclinical students to identify ethical issues and analyse them on a theoretical level. Too often, however, the theoretical information taught in these courses is not utilised when these students become clinical clerks and residents. Without frequent reinforcement, a student's attention to these critical issues declines after medical school (2). If training in the ethical dimensions of medicine is absent in the formative years of residency training (when young clinicians develop enduring practice styles), physicians are likely to conclude that ethical analysis is peripheral to the real work of medicine.

\section{Key words}

Medical ethics; medical education; residency training; communication skills.
More importantly, they will use only their intuition to confront difficult ethical issues in clinical practice, $\overrightarrow{+}$ when more powerful and reliable tools exist.

Although internal medicine residency programmes $\stackrel{6}{-}$ rarely require formal training in medical ethics or in 의 the communication skills necessary for a proper doctor-patient relationship, residency training $ᄃ$ provides a unique opportunity to demonstrate the $\widehat{\Phi}_{\mathbb{D}}$ practical contributions of medical ethics to clinical $\vec{c}$ practice (3). Faced with direct patient care 0 responsibility for the first time, residents are usually quite receptive to learning how to manage ethical problems. Moreover, residents have acquired the expertise necessary to place ethical issues in properō perspective as well as to appreciate fully theirळ్

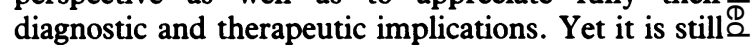
early enough in their careers for ethics programmes to $\overrightarrow{\vec{O}}$ have a profound and lasting impact. Formal training in 3 clinical ethics during the residency years is thus likely? to offer the best opportunity to ensure that future? practising physicians will understand and be able to incorporate the concepts and analytic methods of medical ethics into clinical care.

To give internal medicine residents the cognitive skills necessary to deal with ethical dilemmas, theo General Internal Medicine Residency Training Program at Rhode Island Hospital has designed a을 three-year curriculum in medical ethics. The $D$ programme features a unique integration of ethical theory and communication skills (4). We report here the first four years of our experience to assist other residency programmes in developing similar curricula.

\section{Curricular goals}

The authors designed a clinical ethics curriculum too help residents in the General Internal Medicineo Residency Training Program at Rhode Island Hospital ${ }^{\oplus}$ address the ethical issues that arise in primary care internal medicine. The programme's goal was not to develop moral philosophers, but to help clinicians? apply the principles of medical ethics to their daily $\mathbb{\Omega}$ clinical practice. To accomplish this goal, all residents్ are required to meet the following objectives:

1. Recognise the ethical implications of both inpatien and outpatient clinical cases. This requires tha 
residents be attentive to the moral dimensions of a clinical situation and that they have a basic understanding of ethical concepts.

2. Apply ethical concepts and decision-making procedures to arrive at a well-rounded clinical strategy.

3. Communicate sensitively with patients and other health professionals about these ethical concepts and proposed management plans.

Accomplishing these objectives requires training in both medical ethics and communication skills. The discipline of medical ethics offers the cognitive framework necessary to help residents systematically analyse ethical problems (objectives 1 and 2). However, for training in ethical theory to be useful it must help clinicians solve the ethical problems that arise in clinical care. Ethical theory is best taught, not for its own sake, but as an analytical tool to help resolve clinical problems (5). Moreover, cognitive training in medical ethics alone is not sufficient to produce humane physicians. While able to foster awareness, impart factual knowledge, and encourage critical analysis, training in medical ethics may not by itself change behaviour (6). Even the clearest understanding of an ethical concept, such as informed consent, has little clinical value without the behavioural skills required to converse clearly and sensitively with patients (objective 3 ). Teaching communication skills is directed towards improving these humane behaviours. While ethics helps one decide what to say, communication skills are necessary in order to learn how to express one's thoughts clearly and in a sensitive manner. Together, medical ethics and communication skills provide the necessary foundation for managing medicine's ethical dimensions.

\section{Curriculum}

The General Internal Medicine Residency Program at Rhode Island Hospital has developed a three-year, multidisciplinary programme in medical ethics designed to fulfil the above objectives. The curriculum is divided into two overlapping components:

\section{A. GENERAL CONCEPTS}

This phase of our curriculum has been in place since 1984. A core of ten structured sessions in the first two years of residency training were developed to give residents the necessary observational, cognitive, and behavioural skills. The sessions take place during the residents' month-long ambulatory (outpatient) block. Separated from the exhausting schedule of inpatient medical care, the ambulatory block is a period during which residents focus exclusively on ambulatory medicine and the psychosocial aspects of health care. Scheduling these sessions when residents are neither sleep-deprived nor distracted by the demands of hospitalised patients allows residents to read, concentrate, and thoughtfully reflect on ethical issues.

Behaviourally defined objectives that apply curricular goals to common ethical situations are distributed prior to each session. These objectives, modified from recommendations of the Decamp Conference on the Teaching of Medical Ethics, cover major ethical issues in internal medicine such as the goals of medicine, informed consent, care of the terminally ill, confidentiality, truth telling, and distribution of health care (7) (Table 1). Many of the objectives may seem to imply there are noncontroversial, 'correct' answers to all major moral conflicts in medicine. That interpretation, of course, is not the case. Throughout the curriculum, an effort is made to deepen residents' understanding of the sources of ethical disagreement to help them deal more effectively with value conflicts.

\section{Seminars in medical ethics}

The format of these sessions emphasises group discussions and role-playing rather than didactic lectures, to encourage residents' participation. Individual sessions are taught by a team that incudes a physician, a philosopher with special expertise in medical ethics and a medical communications specialist. Background readings which summarise the salient ethical and clinical points are distributed prior to the session. A philosopher opens each session with a brief overview of the ethical issues raised in the readings. A specific case, drawn from either medical literature or a resident's own caseload, is then presented and discussed. For example, during the session on confidentiality the following case is used:

William M, a 37-year-old man, comes to you for a preemployment physical (medical examination) that is required as part of the company's health insurance programme. He brings you a form which you are to fill out documenting his physical problems and any known medical problems. During the history you find out he is a homosexual and that he recently gave blood but was later called by the blood bank and told his blood cannot be used and that he should not give blood in the future. What should you do?

Residents are asked to choose, and then justify, a particular course of action to other session participants. Often, residents request extra information. They are asked to explain why such information is necessary and how it might change one's behaviour. For example, some residents point out the importance of knowing why the blood was rejected. They may try to justify reporting chronic hepatitis but not reporting a positive HIV test (or vice versa). To emphasise the role of uncertainty in clinical decisionmaking, residents may be asked to make choices based upon incomplete information, for example, if the patient refuses to authorise a phone call to the blood bank. The goal of the discussion is not for the residents to arrive at a 'correct' decision, but to improve the residents' ability to identify the value conflict involved, to propose and justify possible solutions to these conflicts, and to explain how any solution might be 


\section{Table 1. \\ Curricular plan and objectives}

\section{Decision-making regarding life-sustaining measures}

A. Conceptual issues: At the end of the session the resident should be able to:

Discuss the value of the following moral distinctions in guiding decision-making regarding life-sustaining treatments: action $\mathrm{v}$ omission; withholding $\mathrm{v}$ withdrawing treatment; killing $\mathrm{v}$ allowing to die; ordinary $\mathrm{v}$ extraordinary treatment.

B. Policy Issues: At the end of the session the resident should be able to:

1) Counsel patients regarding the use of advance directives. 2) Critically evaluate a hospital's policy on limiting resuscitation. 3) Describe the steps involved in limiting treatment of competent patients.

4) Describe the notion of proxy consent and when it is justified.

C. Communication issues in counselling patients regarding life-sustaining treatment: At the end of the session the resident should be able to: 1) Describe the complexity involved in discussion prognosis. 2) List psychological issues that can interfere with ethical decision-making in cases of terminally ill patients.

3) Clearly and sensitively communicate prognosis and therapeutic options with a terminally ill patient.

4) Clearly and sensitively discuss therapeutic options with an incompetent patient's family.

\section{Informed consent}

A. The goals of medicine: At the end of the session the resident should be able to:

1) Discuss the different goals of medicine and their effect on the doctor-patient relationship. 2) Explain his/ her views about the proper relationship(s) between doctor and patient. 3) Define health and disease and discuss his/her definition's implications for the doctor-patient relationship.

B. The necessary conditions for informed consent: At the end of the session the resident should be able to: 1) State the conditions that are necessary for informed consent. 2) Discuss the notion of competency and its role in informed consent. Justify his/her conception of competency and apply it in clinical practice.

3) Discuss the nature and scope of disclosure necessary for informed consent. 4) Describe justifications for the use of therapeutic privilege.

C. The role of communication in informed consent: At the end of the session the resident should be able to:

1) Clearly communicate information regarding treatment options, uncertainty and prognosis.

2) Distinguish manipulation and coercion from informed consent. 3) List the barriers to informed consent and suggest solutions.

\section{Truth telling}

At the end of the session the resident should be able to:

A. Discuss the ethical issues raised by the obligation to be truthful.

B. Describe and discuss cases in which withholding information may be justified.

\section{Distributive justice}

At the end of the session the resident should be able to:

A. Discuss basic economic facts about health care costs.

B. Describe the value conflicts involved in allocating scarce resources.

C. Discuss the practical and ethical advantages and disadvantages of cost control efforts such as Diagnosis Related Groups (DRGs), external regulation of physicians, financial incentives for physicians, and diagnostic/treatment protocols.

D. Apply the concepts of distributive justice to reach decisions about the allocation of resources in specific cases.

\section{Confidentiality}

At the end of the session the resident should be able to:

A. Decide when it is morally justified to breach confidentiality.

And should:

B. Be familiar with the legal ramifications of Rhode Island laws regarding confidentiality.

\section{Residents' cases}

At the end of the session the resident should be able critically to analyse the ethical implications of a case using the justifications learned in earlier sessions. 
discussed or negotiated with the patient or other relevant parties.

An attending physician (roughly speaking, an independent practitioner with admitting privileges to the hospital concerned), either from the academic staff or a private practitioner, attends each session. This physician is asked to comment on each case's relevance to daily practice, on the practical obstacles to fulfilling ethical ideals and on the way he deals with ethical issues. The involvement of attending physicians helps to ensure that discussions are clinically based and practically orientated. Furthermore, because these physicians are role models for house staff, their participation underscores the importance of the ethical and other humane dimensions of clinical practice. Finally, these physicians themselves learn from their participation in the course, and may thereby become more aware of ethical problems that arise in their own practice and more skilled in the resolution of these problems.

\section{Doctor-patient communication}

A behavioural scientist with special training in doctorpatient communication attends many sessions to teach and to observe how effectively residents discuss difficult ethical issues with patients. There are also three sessions which deal exclusively with the behavioural aspects of clinical ethics. Residents develop their behavioural skills in managing ethically charged situations through video-taped role playing, and observing video-tapes of faculty interacting with standardised actor-patients.

These communication sessions are integral to our ethics curriculum. They illustrate both the behavioural consequences of ethical theory and the challenges of translating theory into clinical practice. Furthermore, the sessions give residents a chance to practise communicating about difficult issues.

\section{Ethical issues in ambulatory (outpatient) medicine}

Traditionally, medical ethics has concentrated on life and death issues which arise in the hospital care of patients. However, philosophers have recently begun to stress the important ethical issues which occur in the outpatient setting (8). To increase residents' awareness of ethical issues in ambulatory care, a philosopher has been leading case-orientated conferences in clinic on a regular basis. The cases often come from resident experiences. A more formal curriculum is being developed to ensure that residents are exposed to the common ethical issues which arise in outpatient medicine.

\section{B. RESIDENTS' APPLICATION OF ETHICAL PRINCIPLES}

The second phase of the curriculum allows residents to integrate the skills and knowledge obtained in the first two years into their clinical practice. This phase, which consists of two components, was first offered in 1986.
Each resident is required to present a patient whose case raises ethical issues to fellow residents and faculty. The resident is responsible for presenting the medical and social facts, analysing the value conflicts in the case, reviewing the pertinent literature and justifying the proposed management plan.

Finally, third-year residents participate in three multidisciplinary sessions, each one involving a case in occupational health, geriatrics or adolescent health (9). The aim of these sessions is to help residents integrate their knowledge of medical ethics into common clinical situations. A case with a bibliography is distributed to the residents prior to the sessions and a faculty resource person identified. Each resident is charged with instructing the other residents about different aspects of the case (for example, the disability law in Rhode Island or issues concerning society's moral obligation to injured workers). After residents present their information, the group attempts to resolve the difficulties in the case. A multidisciplinary panel is available to guide the residents and to ask and answer questions. This experience allows residents to integrate clinical medical ethics with other disciplines in order to solve common but complex clinical problems.

\section{Evaluation}

Although evaluation is an important part of every educational programme, the goals and methods of evaluation in clinical medical ethics training are controversial (10). It is difficult to demonstrate the effectiveness of any single component of medical education in producing skilled clinicians. We do not expect our biochemistry faculty be able to prove that the ability to describe gluconeogenesis improves one's management of diabetic ketoacidosis. Similarly, programmes in medical ethics cannot be expected to demonstrate an immediate effect on resident behaviour. Evaluation of any new curriculum is extremely important for at least two reasons. First, feedback from programme participants can be an important measure of whether stated curricular goals were achieved. Second, this same feedback can be used to modify the curriculum for each subsequent year.

For evaluation of our programme, we have relied heavily on the judgements of the residents themselves, who completed detailed questionnaires about each session at the end of their ambulatory blocks. For both educational and evaluative purposes, each session, therefore, has had explicit, narrowly defined objectives that were stated and distributed in advance. Residents were asked several questions regarding the clarity of the stated objectives and the effectiveness of the individual aspects of each session (for example, readings, discussions, role-playing) in achieving those objectives. Whenever possible, residents were asked to respond by circling one number on a $1-5$ scale.

Because the responses of each group of residents about a session were used to alter the structure or 
content of that session for future residents, it is not strictly possible to present aggregate evaluations for most questions. Two particularly important findings from these evaluations bear emphasis. First, residents in our programme have been extremely receptive to the clinical ethics curriculum and report that this training is useful and improves their perceived ability to manage ethical problems. For example, many of the residents reported that prior to the course they often asked families of acutely ill patients 'What do you want me to do for your mother/father?' However, after learning about the principles of proxy consent and discussing the issue with the communication specialist and chaplain who teach how to talk with families in the intensive care units, residents changed their behaviour. They now ask families 'What would your parent want if he or she were able to talk with us?', believing that this question is both ethically more appropriate and emotionally less distressing. Because of its positive contribution to clinical practice, the residents felt strongly that the curriculum should be a required part of internal medicine training.

Second, residents insist that readings, case discussions, and in fact, every aspect of the curriculum should be closely tied to the practical issues of patient care. Long theoretical readings, or long discussions about moral philosophy were criticised. Although the faculty evaluations also reported satisfaction with the programme, one difficulty in teaching became apparent early in the programme. Integrating the clinical, ethical and behavioural components of each case into a single session turned out to be unwieldy and unduly labour-intensive. A practical solution has been to make the primary focus of each individual session either ethical theory and principles (including case discussions) or communication skills training (including role-playing and video-tapes).

An important measure of any ethics programme's success is its effect on the frequency of explicit discussions of ethical issues in day-to-day clinical care. By this criterion the Rhode Island Hospital programme in clinical ethics has proved to be very successful. The curriculum legitimated the role of ethical analysis in patient care. Since the curriculum began, primary care residents have brought up ethical concerns more frequently in other clinical settings. An ongoing bi-monthly noon conference has been organised to allow residents on the inpatient service to discuss difficult cases in their clinical practices. Residents have also become involved in a variety of other projects which deal with ethical issues in clinical practice, such as serving on the hospital's new ethics committee, assisting in the re-writing of the hospital's policy on resuscitation, and developing research protocols to study this revised policy.

Following the initiation of the formal residency curriculum in ethics, the programme's philosopher was awarded a grant to serve half time for nine months as the hospital's philosopher-in-residence. This opportunity was an important addition to his formal work within the curriculum, allowing him to raise ethical issues with residents during their daily work on the wards and in intensive care units.

The Departments of Medicine and Nursing have also devoted much greater explicit attention to ethical issues during this period. In addition to sponsoring a growing number of grand rounds, other conferences and day-long symposia on ethical issues, an ethics committee has been formed within the Department of Medicine through which physicians, nurses, families, and others can obtain assistance in making difficult ethical decisions in patient care.

\section{Discussion}

In the last few years there has been increasing interest in the ethical and interpersonal dimensions of $\vec{A}$ residency training $(11,12)$. The American Board of $\stackrel{i}{0}$ Internal Medicine, for example, has begun to include evaluations of residents' interpersonal and $\frac{\text { ? }}{2}$ communication skills as a prerequisite for board certification (13). However, few internal medicine residency programmes require formal training in both $\overrightarrow{0}$ medical ethics and communication skills. Rhode $\vec{\bullet}$ Island Hospital's General Internal Medicine Residency Training Program has put into place a three-year curriculum to help residents deal with the ethical dimensions of clinical care. Our programme's special emphasis on improving residents' actual clinical practice has lead to the integration of training in both medical ethics and in communication skills.

Residents have responded enthusiastically to this effort and have reported that the curriculum has had a positive impact on their clinical practice. The programme also has increased residents' sensitivity to ethical issues and has legitimated the inclusion of medical ethics into other aspects of residency training.

We believe that our experience can assist other residency training programmes to institute similar formal curricula in medical ethics. Such programmes, presented to physicians in their formative years, may provide the best chance of producing physicians who exemplify 'integrity, respect and compassion' in their care of patients (13).

\section{Acknowledgements}

The authors thank Drs Dan Brock and Pam Rowland- $\omega$ Morin for their help in structuring and teaching the course; Drs Julie Nissen and Sankey Williams for their 6 insightful comments, and Amy Laub and Mary $\mathbb{D}$ O'Brien for secretarial assistance.

At the time of the study Drs Arnold and Forrow were $\frac{T_{\overrightarrow{0}}}{\mathrm{D}}$ residents at Rhode Island Hospital. Dr Armold is currently $?$ a Veterans Administration Robert Wood fohnson Clinical $\stackrel{\unrhd}{\complement}$ Scholar, Division of General Internal Medicine, University of Pennsylvania. Dr Forrow is a Fellow in the Division of General Medicine, Beth Israel Hospital, 응 Harvard School of Medicine. Dr Wartman is Associate Professor of Medicine and Community Health, Brown $\stackrel{0}{?}$ 
University Program in Medicine, and Director, Division of General Internal Medicine, Rhode Island Hospital. Dr Teno was a Clinical Instructor in Medicine at Rhode Island Hospital, and is currently a Fellow in Geriatrics at Roger Williams Hospital, Providence, Rhode Island, in the United States of America.

Requests for reprints should be addressed to: Steven $A$ Wartman, MD PhD, Division of General Internal Medicine, Rhode Island Hospital, 593 Eddy Street, Providence, RI 02903.

\section{Papers invited}

Critical or philosophical medical ethics teaching is just beginning to take off in Britain and also in other countries in Europe and the Commonwealth. Much careful experiment and mutual learning will be needed to develop successful approaches. One source of important information in this area is the United States and much could be learned both from its successes and its failures in the very extensive experience of medical ethics teaching now available across the Atlantic. This journal will welcome short submissions for its new intermittent series on the teaching of medical ethics; the intention is to provide a national and international exchange of ideas about which ways of teaching medical ethics work well - and which do not.

Papers should be sent to: The Editor, Fournal of Medical Ethics, IME Publications, 151 Great Portland Street, London W1N 5FB. See also Notes on submitting manuscripts for publication at the beginning of the journal.

\section{References}

(1) Pellegrino E D, McElhinney T K. Teaching ethics, the humanities and human values in medical school: A ten-year overview. Washington, D C: Institute of Human Values in Medicine, 1981.

(2) Carlton W. In our professional opinion: The primacy of clinical judgement over moral choice. South Bend, Indiana: University of Notre Dame Press, 1978.

(3) Seigler M. The legacy of Osler: Teaching clinical ethics at the bedside. Fournal of the American Medical Association 1978; 239: 951-955.

(4) Arnold R M, Povar G J, Howel J D. The humanities, humanistic behavior, and the humane physician: A cautionary note. Annals of Internal Medicine. 1987; 2: 313-318.

(5) Agich G J. Evaluating medical ethics teaching. Society of Health and Human Values (notes). 1985; Sept: 3-4.

(6) Goodpaster K E. Is teaching ethics 'making' or 'doing'? Hastings Center Report 1982; 12: 36-39.

(7) Culver C, Clouser K D, Gert B, Brody H, Fletcher J, et al. Basic curricular goals in medical ethics. New England Fournal of Medicine 1985; 312: 253-256.

(8) Barnard D. Unsung questions of medical ethics. Social science and medicine 1985; 21: 243-249.

(9) Colby K K, Almy T P, Zubkoff M. Problem based learning of social sciences and humanities by fourth year medical students. Fournal of medical education 1986; 61: 413-416.

(10) Ruddick W. What should we teach and test? Hastings Center report 1983; 13: 20-22.

(11) Povar G J, Keith K J. The teaching of liberal arts in internal medicine residency training. Fournal of medical education 1984; 59: 714-721.

(12) Boufford J I, Carson R A, eds. The teaching of humanities and human values in primary care training. McLean, Virginia: Society for Health and Human Values, 1984. (Available from the Society for Health and Human Values, 1311A Dolley Madison Boulevard, McLean, VA 22101.)

(13) Subcommittee on Evaluation of Humanistic Qualities in the Internist. A guide to awareness and evaluation of humanistic qualities in the internist. Portland, Oregon: American Board of Internal Medicine, 1985. (Available from the American Board of Internal Medicine, $200 \mathrm{~S} \mathrm{~W}$ Market Street, Portland, OR 97201). 